\title{
Commentary: Mitochondrial targets in the failing right ventricle-multiple opportunities to rescue the right heart in pulmonary hypertension
}

\author{
John G. Augoustides, Professor, MD, FASE, FAHA
}

\footnotetext{
From the Cardiovascular and Thoracic Section, Department of Anesthesiology and Critical Care, Perelman School of Medicine, University of Pennsylvania, Philadelphia, Pa.

Disclosures: Author has nothing to disclose with regard to commercial support.

Received for publication March 3, 2019; accepted for publication March 4, 2019; available ahead of print April 9 , 2019.

Address for reprints: John G. Augoustides, MD, FASE, FAHA, Cardiovascular and Thoracic Section, Department of Anesthesiology and Critical Care, Dulles 680, HUP 3400 Spruce St, Philadelphia, PA 19104-4283 (E-mail: yiandoc@hotmail.com).

J Thorac Cardiovasc Surg 2020;159:141-2

0022-5223/\$36.00

Copyright (C) 2019 by The American Association for Thoracic Surgery

https://doi.org/10.1016/j.jtcvs.2019.03.005
}

Because right ventricular failure with concomitant mitochondrial dysfunction has significant consequences, therapeutic targets to rescue the right side of the heart are important. ${ }^{2-4}$ Mitochondria generate adenosine triphosphate through the oxidative phosphorylation of fatty acids and carbohydrates. ${ }^{5}$ Although fatty acids are their preferred substrate, carbohydrates are more efficient and likely improve cardiac performance in pulmonary hypertension. ${ }^{5}$ Consequently, trials have approached mitochondria as therapeutic targets, including through manipulation of their bioenergetics. ${ }^{2-5}$

The study by Noly and colleagues ${ }^{6}$ in this issue of the Journal highlights the central roles of mitochondria and suggests new therapeutic alternatives in right ventricular failure. In their piglet model of chronic pulmonary hypertension, these investigators demonstrated that mitochondria had impaired oxidative phosphorylation and significant structural damage. ${ }^{6}$ These findings suggest that mitochondrial functional and structural quality together play an important part in right heart failure resulting from pressure overload. ${ }^{6}$

Targeted therapies for the failing right ventricle in pulmonary hypertension must therefore extend beyond metabolic manipulation to address the structural integrity of the mitochondria. ${ }^{5-7}$ Autophagy may be a possibility, because it is a continuous cellular process that recycles cellular components such as mitochondria to maintain homeostasis. $^{5,7}$ Because it also influences the choice of metabolic substrate by myocardial mitochondria, therapeutic manipulation of autophagy in pulmonary hypertension may facilitate not only structural restoration of damaged mitochondria but also a favorable metabolic shift in the failing right ventricle. ${ }^{5,7}$ Autophagy therefore offers the therapeutic potential to address the functional and structural quality of failing mitochondria ${ }^{5-7}$ that has

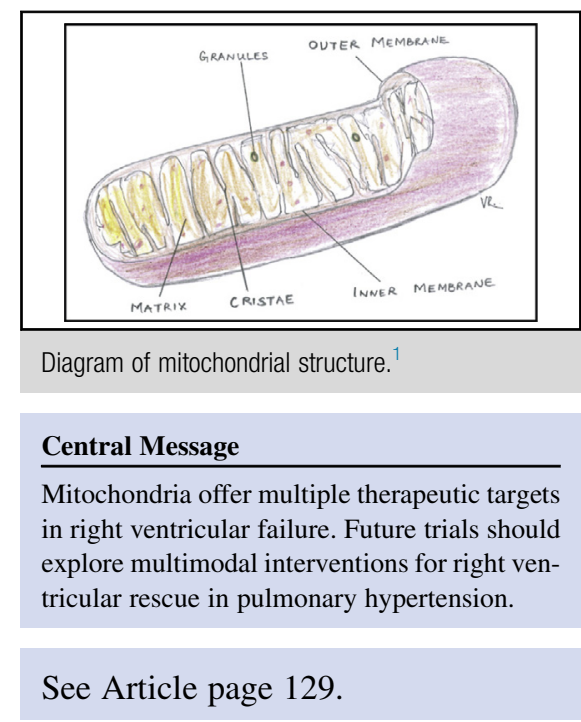

been elucidated in the important work by Noly and colleagues. ${ }^{6}$

Furthermore, mitochondrial dynamics should also be considered. ${ }^{8-10}$ Mitochondrial dynamics include activities such as migration, division (also known as fission), and joining together (also known as fusion). ${ }^{8-10}$ Multiple disorders of mitochondrial dynamics have been implicated in pulmonary hypertension, thereby offering further therapeutic targets for the failing right ventricle. ${ }^{10,11}$ The study by Noly and colleagues ${ }^{6}$ did not address mitochondrial dynamics.

So, where are we, and where do we go from here? Clearly, mitochondrial structure, function, and dynamics are important in right ventricular adaption and subsequent failure. ${ }^{2-11}$ These multiple mechanisms suggest a multimodal therapeutic approach to mitochondrial processes for rescue of the right side of the heart in pulmonary hypertension. An intriguing therapeutic possibility might be mitochondrial transplantation. ${ }^{1,12}$ The injection of autologous healthy mitochondria from skeletal muscle into the failing myocardium may restore mitochondrial quality and provide a multimodal molecular intervention for right ventricular rescue. ${ }^{1,12}$

In conclusion, Noly and colleagues ${ }^{6}$ are to be congratulated for highlighting mitochondrial metabolism and structure in the pathogenesis of right ventricular failure from 
pulmonary hypertension. Their observations add to our understanding of the mitochondrial roles in this pathologic cascade. Future trials will likely focus on interventions to optimize both metabolic and structural processes in the mitochondria of the failing right ventricle. The potential of autophagy and mitochondrial transplantation in this setting merits further investigation. These therapeutic investigations should also consider the mitochondrial dynamics of migration, fission, and fusion.

\section{References}

1. Kumar SR. Mitochondrial transplantation: another miracle of mitochondrial medicine? J Thorac Cardiovasc Surg. 2017;154:284-5.

2. Nagendran J, Gurtu V, Fu DZ, Dyck JR, Haromy A, Ross RB, et al. A dynamic and chamber-specific mitochondrial remodeling in right ventricular hypertrophy can be therapeutically targeted. J Thorac Cardiovasc Surg. 2008;136:168-78. 178.e1-3.

3. Oka N, Wang L, Mi W, Zhu W, Honjo O, Caldarone CA. Cyclosporine A prevents apoptosis-related mitochondrial dysfunction after neonatal cardioplegic arrest. $J$ Thorac Cardiovasc Surg. 2008;135:123-30. 130.e1-2.

4. Rosenfeldt F, Marasco S, Lyon W, Wowk M, Sheeran F, Bailey M, et al. Coenzyme Q10 therapy before cardiac surgery improves mitochondrial function and in vitro contractility of myocardial tissue. J Thorac Cardiovasc Surg. 2005; 129:25-32.

5. Andersen ND. Fueling the heart: shifting the myocardial metabolome by targeting endothelial autophagy. J Thorac Cardiovasc Surg. 2019;157: 194-5.

6. Noly PE, Piquereau J, Coblence M, Ataam JA, Guihaire J, Rucker-Martin C, et al. Right ventricular mitochondrial respiratory function in a piglet model of chronic pulmonary hypertension. J Thorac Cardiovasc Surg. 2020;159: $129-40$.

7. Altanimi TR, Chowdhury B, Singh KK, Zhang L, Mahmood MU, Pan Y, et al. A novel role of endothelial autophagy as a regulator of myocardial fatty acid oxidation. J Thorac Cardiovasc Surg. 2019;157:185-93.

8. Ryan JJ, Archer SL. Emerging concepts in the molecular basis of pulmonary arterial hypertension: part 1: metabolic plasticity and mitochondrial dynamics in the pulmonary circulation and right ventricle in pulmonary arterial hypertension. Circulation. 2015;131:1691-702.

9. Guimaron S, Guihare J, Amsallem M, Haddad F, Fadel E, Mercier O. Current knowledge and recent advances of right ventricular molecular biology and metabolism from congenital heart disease to chronic pulmonary hypertension. Biomed Res Int. 2018;2018:1981568.

10. Ryan J, Dasgupta A, Huston J, Chen KH, Archer SL. Mitochondrial dynamics in pulmonary arterial hypertension. J Mol Med. 2015;93:229-42.

11. Archer SL. Mitochondrial dynamics: mitochondrial fission and fusion in human diseases. N Engl J Med. 2013;369:2236-51.

12. Emani SM, Piekarski BL, Harrild D, del Nido PJ, McCully JD. Autologous mitochondrial transplantation for dysfunction after ischemia-reperfusion injury. $J$ Thorac Cardiovasc Surg. 2017;154:286-9. 